九州大学学術情報リポジトリ

Kyushu University Institutional Repository

\title{
ON THE STRESS-STRAIN BEHAVIOUR OF LIGHTLY CEMENTED CLAY BASED ON AN EXTENDED CRITICAL STATE CONCEPT
}

Kasama, Kiyonobu

Faculty of Engineering, Kyushu University

Ochiai, Hidetoshi

Faculty of Engineering, Kyushu University

Yasufuku, Noriyuki

Faculty of Engineering, Kyushu University

ht tp://hdl. hand le. net/2324/21820

出版情報: Soils and Foundations. 40 (5)，pp.37-47，2000-10-15. 社団法人地盤工学会 バージョン：

権利関係 : 本文データは学協会の許諾に基づきCiNi i から複製したものである 


\title{
ON THE STRESS-STRAIN BEHAVIOUR OF LIGHTLY CEMENTED CLAY BASED ON AN EXTENDED CRITICAL STATE CONCEPT
}

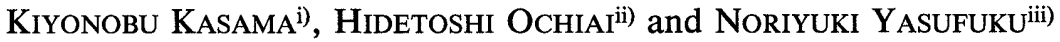

\begin{abstract}
In order to evaluate the effects of increasing cementation on the mechanical properties of lightly cemented soils, artificially cemented clay was prepared and a series of standard consolidation tests, undrained triaxial compression tests and constant mean effective stress tests was performed. Based on the experimental considerations, the effects of light cementation on the stress-strain behaviour and strength property are discussed. In addition, based on the theoretical considerations within the framework of the critical state concept, several basic concepts for the development of a constitutive model for lightly cemented clays are presented. The special characteristic of the presented model is the introduction of an internal variable which controls the effects of cementation. The following conclusions are obtained: 1) The failure state of lightly cemented clay may be determined in the balance of cementation, void ratio and stress condition. 2) The failure state line in the $p-q$ space is parallel to that of an uncemented clay and has a certain intercept $p_{r}$, which characterizes the cementation effect. The slope of the failure state line in the $e-\ln \left(p+p_{r}\right)$ space becomes steeper with any increase in cementation effect. 3) A constitutive model incorporating cementation is proposed. Introduction of a soil constant $p_{r}$ is effective in estimating the mechanical properties of lightly cemented clay.
\end{abstract}

Key words: Cam-Clay, cement, cementation, cement stabilization, clay, constitutive equation of soil, shear strength, triaxial compression test (IGC: D6/D10)

\section{INTRODUCTION}

Cement stabilization is considered to be effective in increasing the bearing capacity, reducing the effective weight of the soil, preventing liquefaction and immobilizing waste (Terashi, 1994; Zen, 1994). Therefore, cement stabilization has been used to increase the stability of structure, create man-made ground and utilize waste. However, cement stabilized soils are widely recognized as possessing an inherent cohesion due to the cementation between the individual soil particles, and the mechanical properties of these soils become more complex depending on the degree of cementation. Considering the prevalence of cement stabilization and the future development of waterfront structures, it is essential to clarify their mechanical behaviour and to propose an analytical method for the boundary value problems relating to cement stabilized ground.

In past experimental studies on cement stabilized soil, the effects of cement content, curing periods, and mixing condition on the mechanical properties have been examined mainly using the unconfined compression test (e.g.
Terashi et al., 1977 and 1980). It is recognized that the stress-strain relationship depends on the degree of cementation and the confining pressure (e.g. Yajima et al., 1997; Leroueil and Vaughan, 1990). The component of strength due to cementation generally increases as the degree of cementation increases. However, in relation to the friction angle, Clough et al. (1981) and Zen et al. (1990) suggested that the friction angle was the same as for the comparable uncemented soils; on the other hand, Ue et al. (1997) and Lambe (1960) asserted that they were larger than the value of uncemented soils. Lade and Overton (1989) proposed a failure criterion incorporating the degree of cementation. Matsuoka and Sun (1993) extended the concept of a Spatially Mobilized Plane to cement stabilized soil. These failure criteria contain a term incorporating cementation and can also represent the increase in strength as cementation increases.

In recent years several constitutive models have been developed to include the effect of cementation. Gens and Nova (1993) and Liu et al. (1997) proposed the basic conceptual requirements for the development of a constitutive model for cement stabilized soil, so that it fitted

i) Research Associate, Department of Civil and Structural Engineering, Graduate School of Engineering, Kyushu University, 6-10-1, Hakozaki, Higashi-ku, Fukuoka 812-8581.

ii) Professor, ditto.

iii) Associate professor, ditto.

Manuscript was received for review on May 10, 1999.

Written discussions on this paper should be submitted before May 1, 2001 to the Japanese Geotechnical Society, Sugayama Bldg. 4F, Kanda Awaji-cho 2-23, Chiyoda-ku, Tokyo 10-0063, Japan. Upon request the closing date may be extended one month. 
within the framework of hardening plasticity. Yu et al. (1998) also proposed a model for artificially cemented soil in the frame of the continuous damage theory.

Based on these experimental and theoretical studies, the mechanical properties of cement stabilized soil have become gradually clear. However, in order to standardize the effect of cementation on the mechanical properties, a systematic approach is still needed in relation to the magnitude of cementation. Particularly, it is important to evaluate the changes of properties with increasing cementation from those of uncemented soils. Further, soil has intrinsic properties, by which the strength and stiffness increase with increasing density and confining pressure. Thus, these intrinsic properties should be reflected in future cement stabilization together with the effect of cementation.

In this study, an artificially cemented clay is first made by mixing clay with cement to create a lightly cemented clay. A series of standard consolidation tests, undrained triaxial compression tests and constant mean effective stress tests was performed to evaluate the effects of increasing cementation on the stress-strain behaviour and strength properties. Based on the experimental findings, a failure state concept and a new equation of internal dissipated energy are presented within the framework of the critical state concept. Finally, an elasto-plastic constitutive model incorporating the effects of cementation is presented and verified. Note that the terms of effective stress in this paper are depicted without apostrophes.

\section{STRESS-STRAIN BEHAVIOURS}

\section{Sample Preparation and Test Procedure}

In order to create samples with light cementation, a slurry containing Portland Cement was mixed with Ariake Clay $\left(w_{L}=86.5 \%, I_{p}=51.3, \rho_{s}=2.609 \mathrm{~g} / \mathrm{cm}^{3}\right)$ in a slurry of $2 w_{L}$ water content. A schematic diagram of sample preparation is shown in Fig. 1. In preparing the samples, cement contents of $1 \%, 3 \%$, and $5 \%$ per dried sample weights were selected. Each reconstituted clay mixed with either $1 \%, 3 \%$, or $5 \%$ cement content, namely $1 \%$ Clay, $3 \%$ Clay and $5 \%$ Clay, was consolidated in one dimension up to $49 \mathrm{kPa}$ confining pressure. After the consolidation period was completed (as decided by the $3 t$ method), the consolidated samples were wrapped in moisture proof bags and cured for 30 days in a humid room under atmospheric pressure at a temperature of $20 \pm 3^{\circ} \mathrm{C}$. Figure 2 shows the changes of the void ratio for samples during consolidation and the $90 \%$ consolidation time for each sample, which was decided by the $\sqrt{t}$ method. It can be seen that the void ratio of the samples after consolidation becomes larger as the cement content increases, and also that the $90 \%$ consolidation time decreases as the cement content increases.

A series of standard consolidation tests and undrained triaxial compression tests were performed according to the JGS (Japanese Geotechnical Society) standards 04111990 and 0523-1990 respectively, together with constant mean effective stress tests.

\section{Strength and Deformation Properties}

The compression curves of lightly cemented clay are shown in Fig. 3 in $e-\log \sigma_{v}$ space. It is noted that the consolidation yield stress increases with the increase in cementation, despite the fact that all initial specimens are prepared under the same vertical effective stress $49 \mathrm{kPa}$. In fact, the normally consolidated lines are located above that of uncemented clay.

Figure 4 shows the stress-strain relationships at a confining pressure of $294 \mathrm{kPa}$ during undrained triaxial compression tests. It can be observed that the stressstrain relationships show a clear trend from strain hardening to post-peak strain softening behaviour as the cementation increases. The peak deviator stress, $q_{f}$, and the void ratio after consolidation, $e_{i}$, are plotted in Fig. 5 . It is interesting to point out that they $q_{f}$ of $1 \%$ Clay and $3 \%$ Clay are almost the same as that of $0 \%$ Clay, although void ratio $e_{i}$ becomes larger with the increasing cementation. As for 5\% Clay, $q_{f}$ shows the largest value within the four kinds of specimen in spite of having the largest $e_{i}$. Figure 6 shows the peak deviator stress $q_{f}$ against the void ratio after consolidation, $e_{i}$. It is observed that $q_{f}$ increases with the increasing cementation in comparison with the same void ratio. These results show that the shear strength of lightly cemented clay can be evaluated as a function of confining pressure, void ratio and the degree of cementation.

The undrained stress-path in $p-q$ space is shown in Fig. 7. The full straight line in this figure shows the critical state line of uncemented clay. It can be seen that the failure state of lightly cemented clay is located above the critical state line of uncemented clay, where the failure state means the stress state indicating a peak deviator stress under undrained conditions.

The value of stress, $p_{r}$, at the intersection point of the failure state line with $p$-axis and the slope of the failure state line in $p-q$ space are plotted in Fig. 8. It can be observed that at low confining pressures up to $294 \mathrm{kPa}$, the slope is almost constant irrespective of different cement contents, while the $p_{r}$ increases with the increasing cement content. This means that the $p_{r}$ can be considered to be one of the parameters representing cementation.

The failure state in $e-\ln p$ space is shown in Fig. 9. It can also be observed that the failure state is located above the critical state line of uncemented clay, especially at low confining pressure. In addition, the failure state seems gradually to approach that of uncemented clay as the confining pressure increases.

The stress ratio-shear strain, and volumetric strainshear strain relationships are shown in Fig. 10 based on constant mean effective stress tests. The stress ratio at the same shear strain increases as the cementation increases; however, the amount of volumetric strain seems not to indicate any particular trend. It can be considered that the stress condition of 5\% Clay becomes slightly overconsolidated due to cementation. The stress-dilatancy relationships in the expected stress range of normal consolidation are shown in Fig. 11.

Based on the above experimental results of lightly 
Procedure(1)

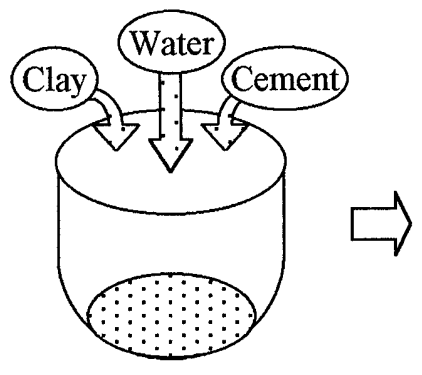

-Mixing cement with clay slurry

- Adjustment of water content to

2 times water content of liquid limit

Procedure(6)

- Standard consolidation test, tiriaxial compression test and constant mean effective stress test performed using sample trimmed from sample in procedure(5)
Procedure(2)

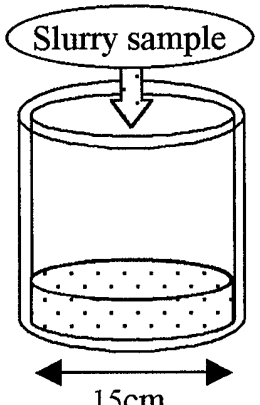

$15 \mathrm{~cm}$

- Pouring of cement slurry into mould

Procedure(5)

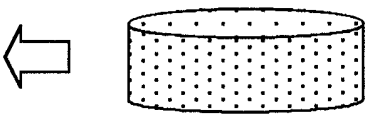

- Sample taken from mould after consolidation, wrapped in moisture proof bag and cured for 30days
Procedure(3)

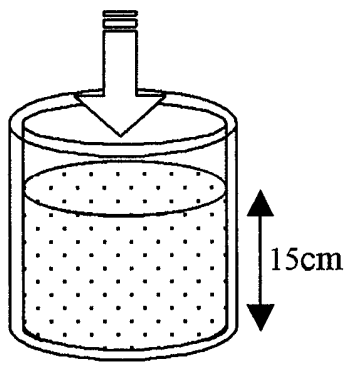

- Consolidation of slurry sample up to $49 \mathrm{kPa}$ in mould<smiles>C1CCCC1</smiles>

Procedure(4)

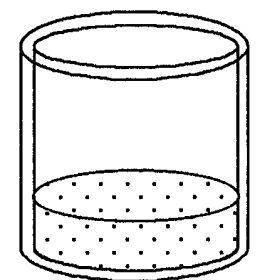

- Consolidation period decided by $3 \mathrm{t}$ method (11days)

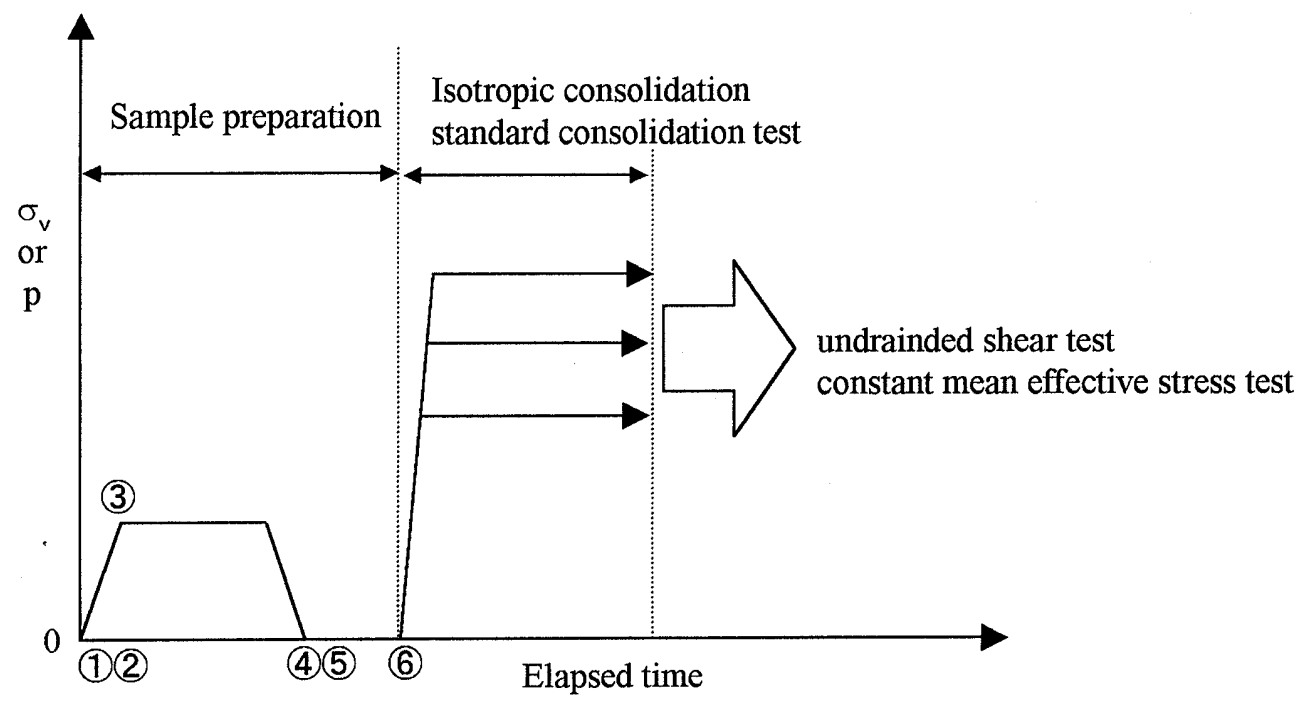

Fig. 1. Schematic diagram of sample preparation

cemented clays up to $5 \%$ cement contents, the effects of cementation on the stress-strain behaviour are summarized as follows:

1) The normally consolidated line in $e-\log \sigma_{v}$ space is shifted right with the increase in cementation and also the consolidation yield stress increases with the increasing cementation (see Fig. 3).

2) The peak deviator stress $q_{f}$ may be determined in the balance of cementation, void ratio and stress condition (see Fig. 6).
3) The failure state line of lightly cemented clay in $p-q$ space is parallel to that of uncemented clay and has a certain intercept which characterizes the effect of cementation (see Figs. 7 and 8).

4) The failure state in $e-\ln p$ space is located above the critical state line of uncemented clay and seems gradually to approach that of uncemented clay as the confining pressure increases (see Fig. 9).

5) The lightly cemented clay in the normal consolidation indicates compressive behaviour during shear and 


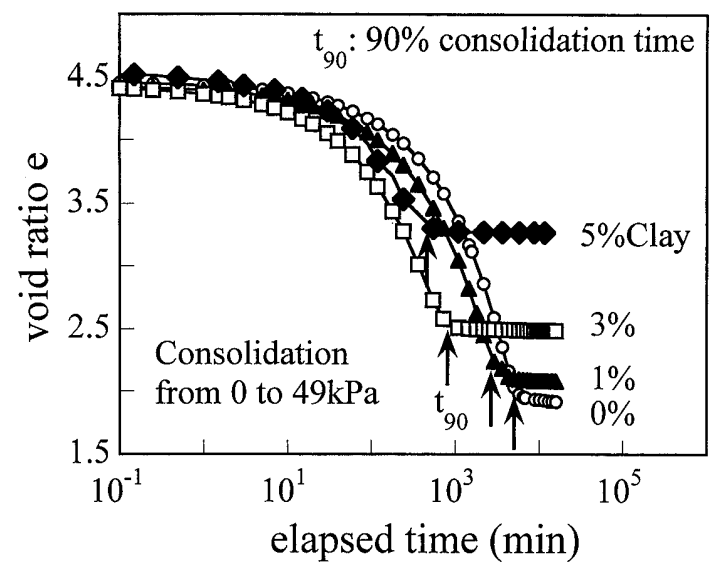

Fig. 2. Change of void ratio during sample preparation

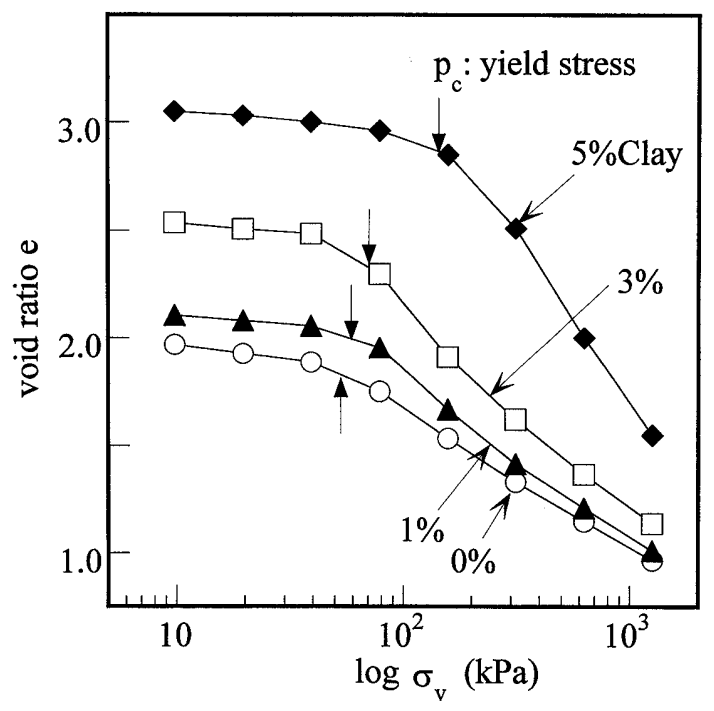

Fig. 3. One dimensional compression curves

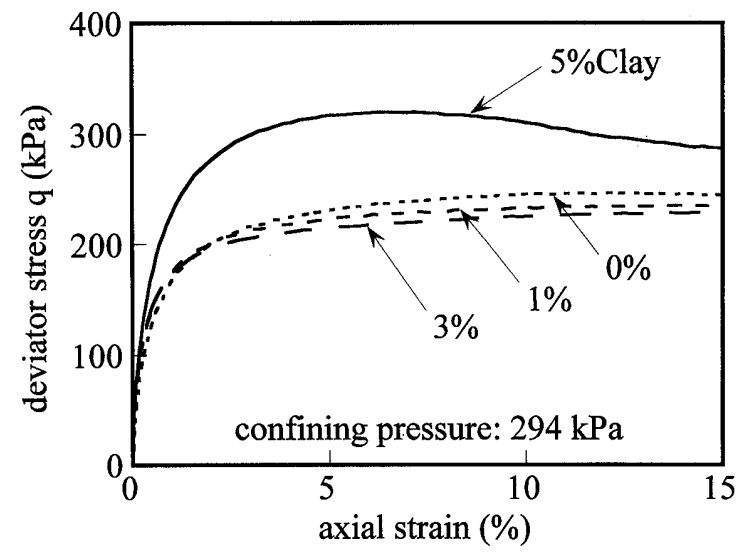

Fig. 4. Stress-strain relationship of clay with various cement contents

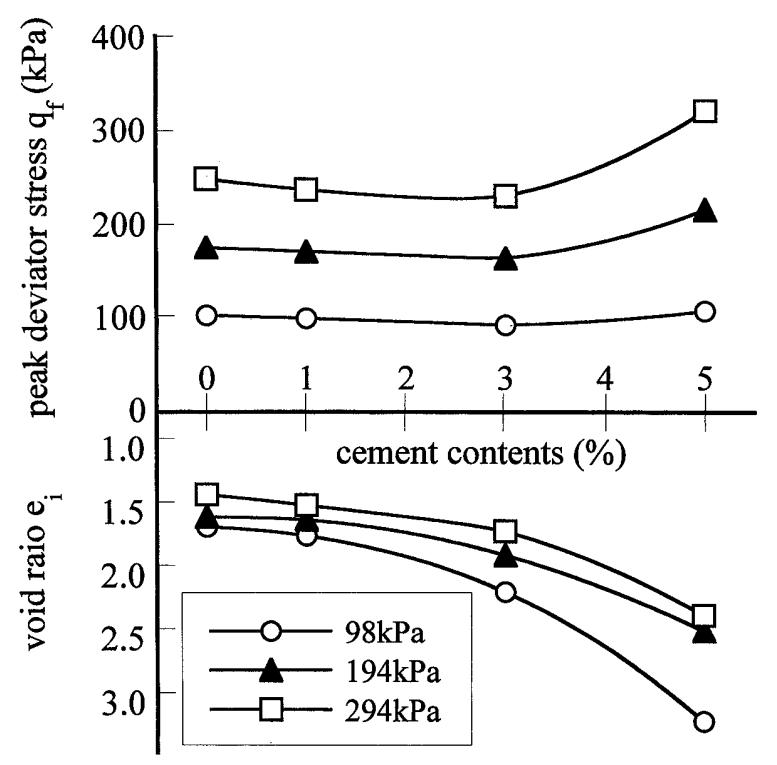

Fig. 5. Peak deviator stress and initial void ratio against cement contents

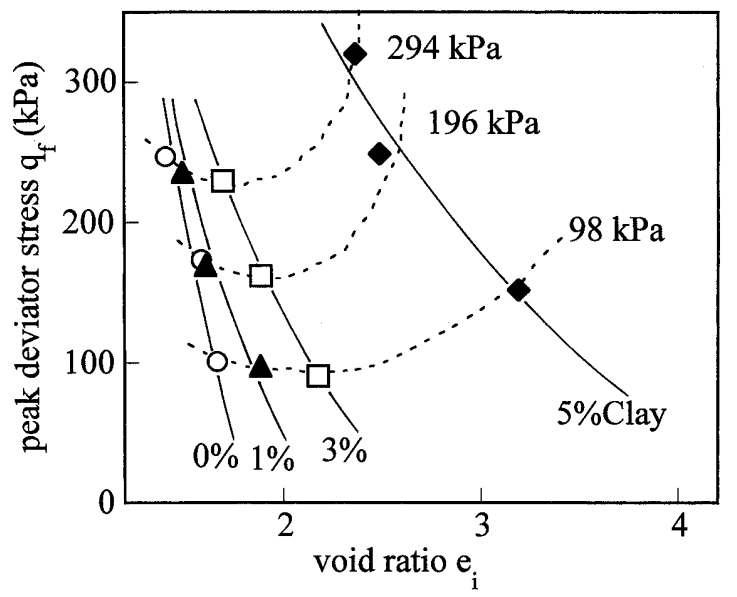

Fig. 6. Peak deviator stress against void ratio

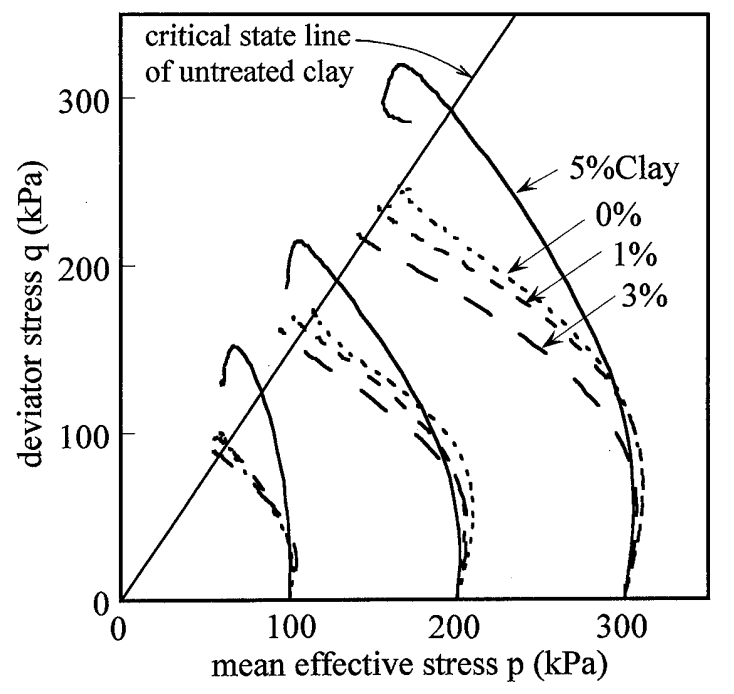

Fig. 7. Stress-path of lightly cemented clays 

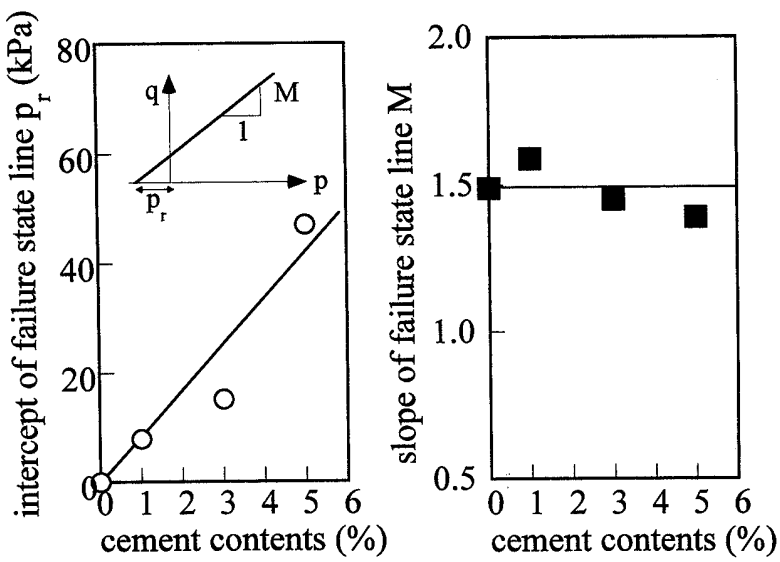

Fig. 8. Intercept and slope of failure state line

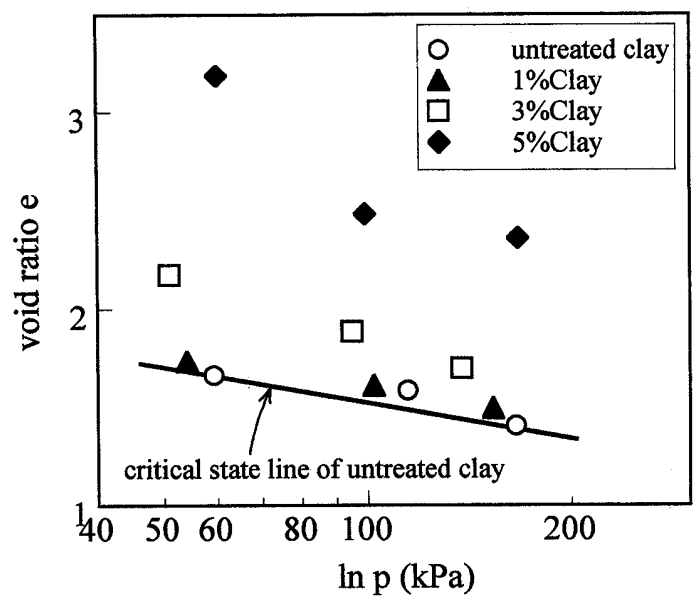

Fig. 9. $e-\ln p$ relationships with cementation at failure state

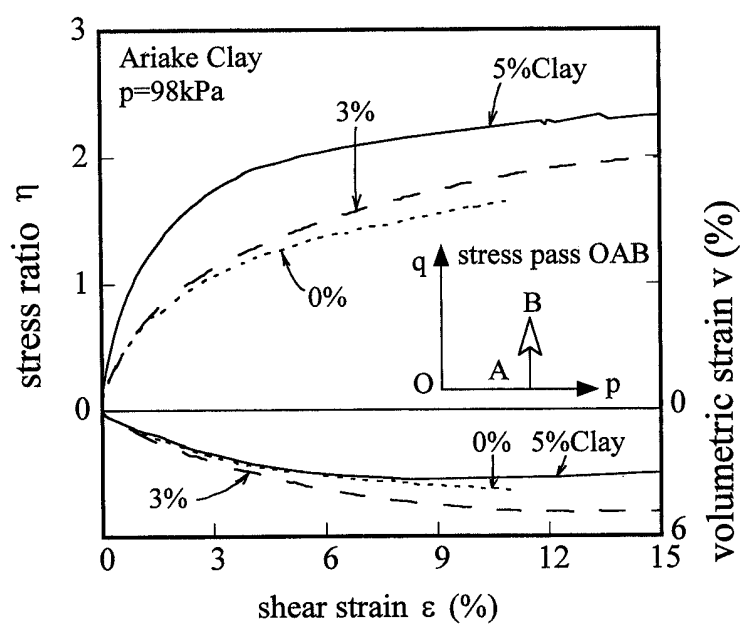

Fig. 10. Experimental results of constant mean effective stress test

the degree of compression is emphasized with the increasing cementation. The consolidation yield stress is increased by the effect of cementation, which induces lightly cemented clay to behave as overconsolidated soil and then the dilative behaviour is emphasized (see Fig. 10).

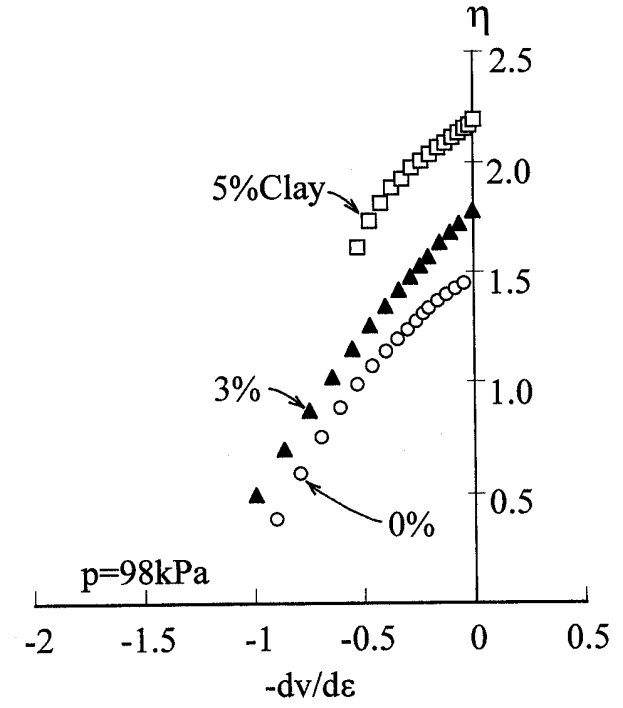

Fig. 11. Stress-dilatancy relationships based on constant mean effective stress tests of lightly cemented clay

6) The stress-dilatancy relationship is almost parallel with that of uncemented clay and is located upward with the increasing cementation (see Fig. 11).

\section{EVALUATION OF STRESS-STRAIN BEHAVIOURS USING EXTENTED CRITICAL STATE CONCEPT}

\section{Generalization of Internal Energy Equation}

In order to estimate the changes in the stress-strain behaviour of lightly cemented clay, theoretical considerations can be made on the basis within the framework of the critical state concept.

The considerations mentioned in this paper are restricted to the axisymmetric stress states. However, extension to the general stress state, which has already been described by Yasufuku et al. (1997), is not so difficult. The following stress and strain increment parameters are used in this study,

$$
\begin{gathered}
p=\frac{1}{3}\left(\sigma_{1}+2 \sigma_{3}\right), \quad q=\sigma_{1}-\sigma_{3} \\
d v^{p}=d \varepsilon_{1}+2 d \varepsilon_{3}, \quad d \varepsilon^{p}=\frac{2}{3}\left(d \varepsilon_{1}-d \varepsilon_{3}\right)
\end{gathered}
$$

where, $\sigma_{1}$ and $\sigma_{3}$ are the maximum and minimum principal effective stress, respectively, and $d \varepsilon_{1}$ and $d \varepsilon_{3}$ are the maximum and minimum principal strain increment, respectively. Here $d \varepsilon^{p}$ and $d v^{p}$ represent the plastic shear and volumetric strain increments, respectively, and $q$ and $p$ are well known Cam-Clay parameters (Eq. (1)) for deviator stress and mean effective stress, respectively. An external dissipated energy equation under triaxial conditions is generally expressed as;

$$
d W_{\text {out }}=p d v^{p}+q d \varepsilon^{p}=p \sqrt{\left(d v^{p}\right)^{2}+2 \eta d v^{p} d \varepsilon^{p}+\left(\eta d \varepsilon^{p}\right)^{2}}
$$

where, $d W_{\text {out }}$ is an external dissipated work per unit volume, and $\eta$ is a Cam-Clay parameter defined as $\eta=q / p$. In the case of isotropic compression $(q=0$, 

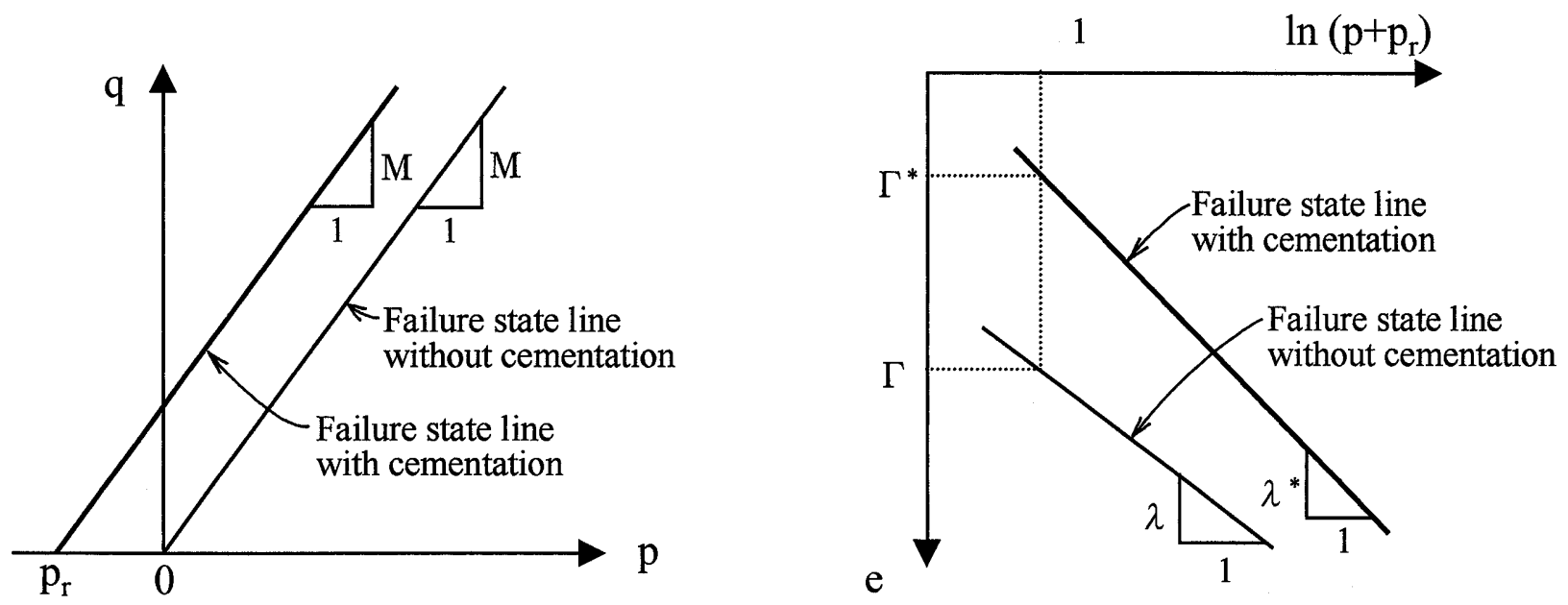

Fig. 12. Schematic diagram of failure state line introducing cementation effect

$d \varepsilon^{p}=0$ ), Eq. (3) is given by:

$$
d W_{o u t}=p d v^{p}
$$

For the critical state $\left(q / p=M, d v^{p}=0\right)$, Eq. (3) is given by:

$$
d W_{\text {out }}=q d \varepsilon p=p M d \varepsilon^{p}
$$

In order to standardize an internal dissipated energy work $d W_{\text {in }}$ based on Eq. (3), $d W_{\text {in }}$ is needed to include individual terms of $p, d \varepsilon^{p}$ and $d v^{p}$ and a coupling term of $d \varepsilon^{p}$ and $d v^{p}$, which is satisfied with Eqs. (4) and (5). In this way, a generalized internal energy $d W_{\text {in }}$ can be presented by the following equation (Yasufuku, 1995; Yasufuku et al. 1997):

$$
d W_{\text {in }}=p \sqrt{\left(d v^{p}\right)^{2}-X d v^{p} d \varepsilon^{p}+\left(M d \varepsilon^{p}\right)^{2}}
$$

The term " $X d v^{p} d \varepsilon^{p}$ ", can be considered to be the coupling term concerning soil dilatancy in which $X$ is a factor which characterizes the material property. It is especially important to emphasize that when $X=0$, Eq. (6) represents the internal dissipated energy work of the Modified Cam-Clay model and also when $X=(M-\eta)$, Eq. (6) represents the internal dissipated energy work of the Cam-Clay model (Roscoe and Burland, 1968; Schofield and Wroth, 1968).

\section{Failure State Condition with Cementation}

The critical state of normally consolidated clays in $p-q$ and $e-\ln p$ space are generally given by:

$$
\begin{aligned}
& q=M p \\
& e=\Gamma-\lambda \ln p
\end{aligned}
$$

where $\Gamma$ is the void ratio $e$ for the critical state at which $p$ is unit pressure, $\lambda$ is the slope of critical state line and/or normally consolidated line, and $M$ is the Cam-clay parameter which describes the stress ratio at the critical state. When clay is normally consolidated, the critical state can be considered as a failure state.

At the failure state for lightly cemented clay, the effects of cementation ought to make the strength of clay increase, and extend the stress domain in which the clay can exist in $p-q$ space and $e-\ln p$ space. In order to introduce a cementation effect into the above failure state condition, two assumptions are made (see Fig. 12):

1) The failure line of cemented clay in $p-q$ space is parallel to that of uncemented clay and is shifted along the $p$ axis by a cementation effect described as $p_{r}$, which is based on the results in Figs. 7 and 8. A similar assumption for cemented sand in $\tau-\sigma$ space was also made by Matsuoka and Sun (1993).

2) The failure state line in $e-\ln \left(p+p_{r}\right)$ space is represented by a linear relationship and the slope of this line is steeper than that for uncemented, which is extended on the basis of the results in Fig. 9.

According to the above assumptions, the failure state line in $p-q$ and $e-\ln \left(p+p_{r}\right)$ space is extended as follows:

$$
\begin{aligned}
& q=M\left(p+p_{r}\right) \\
& e=\Gamma^{*}-\lambda^{*} \ln \left(p+p_{r}\right)
\end{aligned}
$$

where, $p_{r}$ is a parameter defined as a value of $p$ at $q=0$, which means that the cementation effect inherently exists at failure state. $M$ is given by modified stress ratio $\eta^{*}$ at failure state, in which $\eta^{*}$ is defined by:

$$
\eta^{*}=\frac{q}{p+p_{r}}
$$

\section{Introduction of Cementation Effect into the Energy Equation}

In order to introduce the cementation parameter $p_{r}$ into a generalized internal dissipated energy as shown in Eq. (6), the following internal dissipated energy with cementation is introduced such that:

$$
d W_{i n}=p^{*} \sqrt{\left(d v^{p}\right)^{2}-X d v^{p} d \varepsilon^{p}+\left(M d \varepsilon^{p}\right)^{2}}-p_{r} d v^{p}
$$

where, $p^{*}$ is defined as follows:

$$
p^{*}=p+p_{r}
$$


It is important to note that when $p_{r}=0$, Eq. (12) reduces to Eq. (6). In the case of isotropic compression ( $q=0$, $\left.d \varepsilon^{p}=0\right)$, Eq. (12) is given by:

$$
d W_{\text {in }}=p^{*} d v^{p}-p_{r} d v^{p}=p d v^{p}
$$

It is noted that the cementation parameter $p_{r}$ is not included in Eq. (14). On the other hand, for the failure state $\left(\eta^{*}=M, d v^{p}=0\right)$, Eq. (12) is given by:

$$
d W_{i n}=p_{f}^{*} M d \varepsilon^{p}=\left(p+p_{r}\right) M d \varepsilon^{p}=q_{f} d \varepsilon^{p}
$$

where, $q_{f}$ is the deviator stress at the failure state. In Eq. (15), the cementation parameter $p_{r}$ is included and this means that the cementation effect can be mainly mobilized due to shear. Using modified stress $p^{*}=p+p_{r}$ and stress ratio $\eta^{*}=q / p^{*}$, the stress-dilatancy relationship with cementation can be expressed as follows:

$$
\frac{d v^{p}}{d \varepsilon^{p}}=\frac{M^{2}-\eta^{* 2}}{X+2 \eta^{*}}=\frac{M^{2}-\eta^{* 2}}{c \eta^{*} \quad \text { at } X=(c-2) \eta^{*}}
$$

The last term of Eq. (16) assumes that the stress-dilatancy relationship can be expressed by a hyperbola and the constant $c$ is the experimental parameter, in which $2 / c$ is the slope of tangent to the hyperbola at point $\eta^{*}=M$. As shown in Fig. 13, various stress-dilatancy relationships can be expressed by varying the parameter $X$. By changing the value of $p_{r}$ with respect to mean effective stress $p$, the effect of cementation on the stress-dilatancy relationship may be evaluated as shown in Fig. 14. The stressdilatancy relationship is shifted upwards as cementation effect $p_{r}$ increases. The resulting stress-dilatancy relationship, obtained by using modified stress ratio $\eta^{*}$, coincides with the curve in the case of $p_{r} / p=0$. It should be emphasized that the stress-dilatancy relationship of cemented clay can be uniquely evaluated using the modified stress ratio $\eta^{*}$ incorporating the effect of cementation.

\section{Yield Function and Undrained Stress-Path}

When the cementation effect is introduced, the yield function has the following general form:

$$
f\left(p^{*}, q, p_{0}^{*}\right)=0
$$

where, $p^{*}=p+p_{r}, p_{0}^{*}=p_{0}+p_{r}$ and $p_{0}$ is a hardening parameter. Based on the framework of the critical state concept, the hardening modulus is represented in the next equation.

$$
H_{p}=-\frac{(1+e) p_{0}^{*}}{\lambda^{*}-\kappa^{*}}\left(\frac{\partial f}{\partial p_{0}^{*}}\right)\left(\frac{\partial f}{\partial p^{*}}\right)
$$

The yield function with cementation is considered here. By applying the normality rule to Eq. (16), the yield function can be derived, which is dependent on parameter $c$, such that:

$$
\begin{aligned}
c=1: f & =q^{2}+2\left(M p^{*}\right)^{2} \ln \left(\frac{p^{*}}{p_{0}^{*}}\right)=0 \\
\frac{\partial f}{\partial p^{*}} & =2 p^{*}\left(M^{2}-\eta^{* 2}\right) ; \frac{\partial f}{\partial q}=2 q ;
\end{aligned}
$$

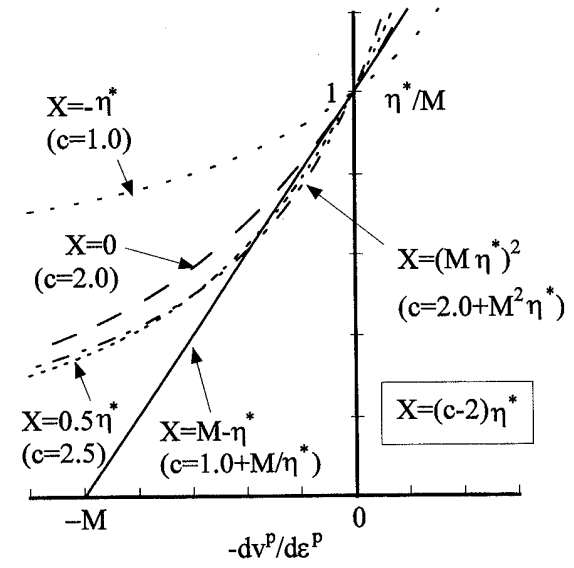

Fig. 13. Examples of computed stress-dilatancy relationships

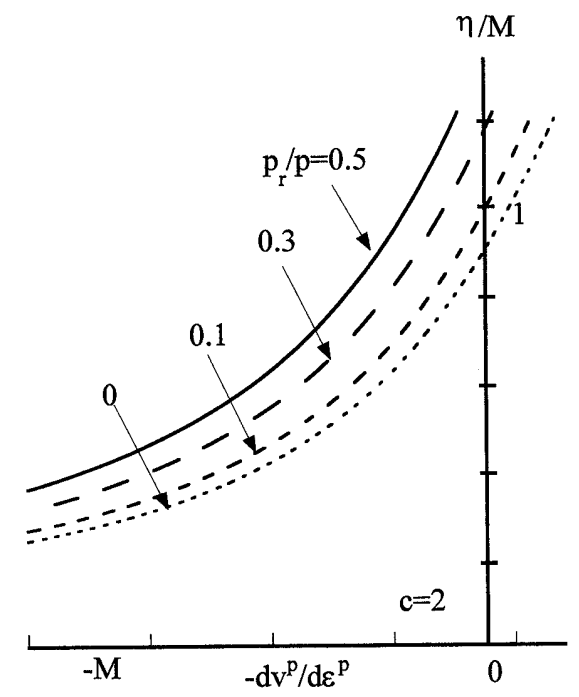

Fig. 14. Computed stress-dilatancy relationships of lightly cemented clays

$$
\begin{gathered}
\frac{\partial f}{\partial p_{0}^{*}}=-\frac{2 M^{2} p^{* 2}}{p_{0}^{*}} \\
c \neq 1: f=p^{* 2}-p^{* 2}\left(\frac{p_{0}^{*}}{p^{*}}\right)^{2(c-1) / c}+\frac{(c-1)}{M^{2}} q^{2}=0 \\
\frac{\partial f}{\partial p}=\frac{2(c-1) p^{*}}{c M^{2}}\left(M^{2}-\eta^{* 2}\right) ; \frac{\partial f}{\partial q}=\frac{2(c-1) q}{M^{2}} ; \\
\frac{\partial f}{\partial p_{0}^{*}}=-\frac{2(c-1) p^{*}}{c}\left(\frac{p_{0}^{*}}{p^{*}}\right)^{(c-2) / c}
\end{gathered}
$$

where these equations satisfy an initial condition in which $\eta^{*}=0$ when $p=p_{0}^{*}$. This yield function includes the new parameters $c$ and $p_{r}$. In order to evaluate the effect of parameter $c$ on the yield curve, yield curves with varying parameter $c$ are shown in Fig. 15. The shape changes elliptically with the increasing parameter $c$. Figure 16 shows the yield curves with variation of $p_{r}$. In both cases it can be observed that the yield curve extends to the extension side of the $p$ axis with increasing values 


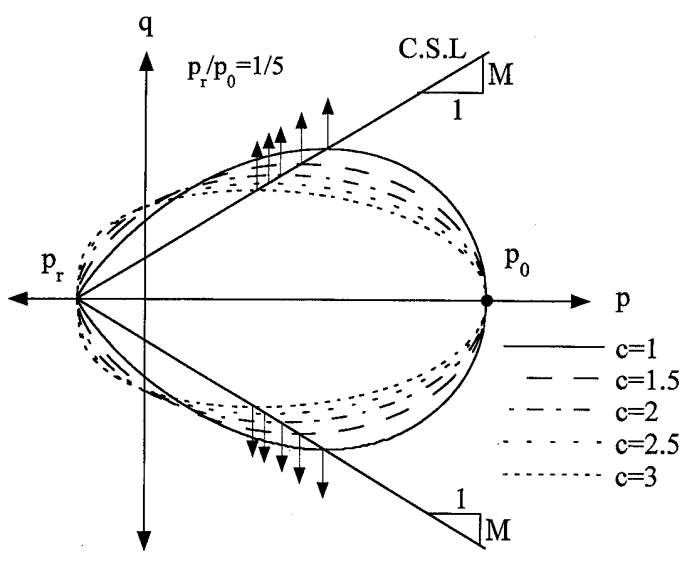

Fig. 15. Effect of constant "c"' on yield curve

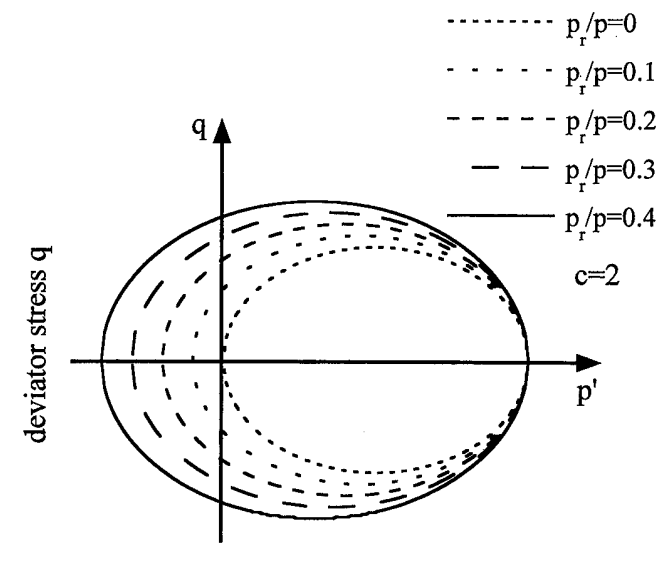

mean effective stress $p$

Fig. 16. Yield curves introducing cementation effects

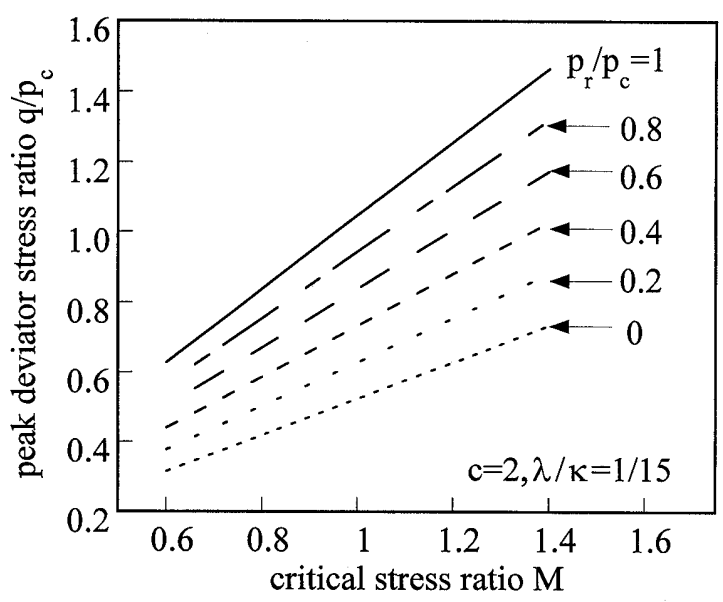

Fig. 17. Effects of cementation on peak deviator stress

of $p_{r}$. This extension of the yield curve theoretically explains the existence of tension strength in lightly cemented clay.

Based on the new internal dissipated energy and the failure state concept, the undrained stress-path in $p-q$ space is given by:

$$
\begin{aligned}
& c=1: \frac{p^{*}}{p_{0}^{*}}=\exp \left\{-\left(1-\frac{\kappa^{*}}{\lambda^{*}}\right) \frac{\eta^{* 2}}{2 M^{2}}\right\} \\
& c \neq 1: \frac{p^{*}}{p_{0}^{*}}=\left\{\frac{M^{2}}{(c-1) \eta^{* 2}+M^{2}}\right\}^{c\left(1-\kappa^{*} / \lambda^{*}\right) / 2(c-1)}
\end{aligned}
$$

The evaluation of undrained strength in closed form seems to be useful from a practical point of view. By substituting $\eta^{*}=M$ into the above equation, the normalized undrained strength, i.e. the value of the undrained shear strength $q_{f}$ divided by initial mean effective stress $p_{c}$ at the undrained condition, is estimated, and $q_{f} / p_{c}-M$ relationships are shown in Fig. 17.

\section{APPLICATION TO ARTIFICIALLY CEMENTED CLAY}

\section{Verification of the Failure State Concept and the Energy Equation}

The failure state of all cemented clays in $e-\ln \left(p+p_{r}\right)$ space is shown in Fig. 18. Here, the value of $p_{r}$ shown in Fig. 8 is used. It can be seen that the failure state is to be represented by linear relationship in the $e-\ln \left(p+p_{r}\right)$ space and that the slope increases as the cementation increases.

In order to verify Eq. (16), the resulting relationships obtained by rearranging Fig. 11 using $\eta^{*}$ are shown in Fig. 19. The curves using the stress-dilatancy equation in Eq. (16) are also shown in this figure. It should be emphasized that the stress-dilatancy relationships can be uniquely evaluated using modified stress ratio $\eta^{*}$. Predicted stress-dilatancy relationship, when $c=2.0$ in Eq. (16), gives good agreement with observed one except for relatively low stress rations. The plastic volumetric strain during constant mean effective stress tests based on the proposed model is affected by the compressibility of lightly cemented clay, the void ratio after consolidation and the stress history as explained in Appendix A.

The above considerations demonstrate the effectiveness of the failure state concept and the energy equation.

\section{Comparison with Experimental Data}

The capability of the proposed constitutive model will be demonstrated for undrained triaxial compression tests. Six constants are needed to predict the stress-strain curves, in which four constants are Cam-Clay parameters and the other constants $c$ and $p_{r}$ are newly introduced. Here, the value of $c$ is set at 2.0 based on Figs. 13 and 19. The soil constants are summarized in Table 1.

Figure 20 shows the predicted undrained stress-path in $p-q$ space. It can be seen that the stress-path of 3\% Clay is below that of $0 \%$ Clay and the stress-path of $5 \%$ Clay is above that of $0 \%$ Clay. Predicted failure state lines have an intercept in the $p-q$ space, which rationalizes the characteristic of the test results in Fig. 7. The excess pore water pressure based on the proposed model is mainly affected by the compressibility of lightly cemented clay and cementation parameter, $p_{r}$, and increases as the cementation increases, as explained in Appendix B.

The predicted and observed peak deviator stresses $q_{f}$ 


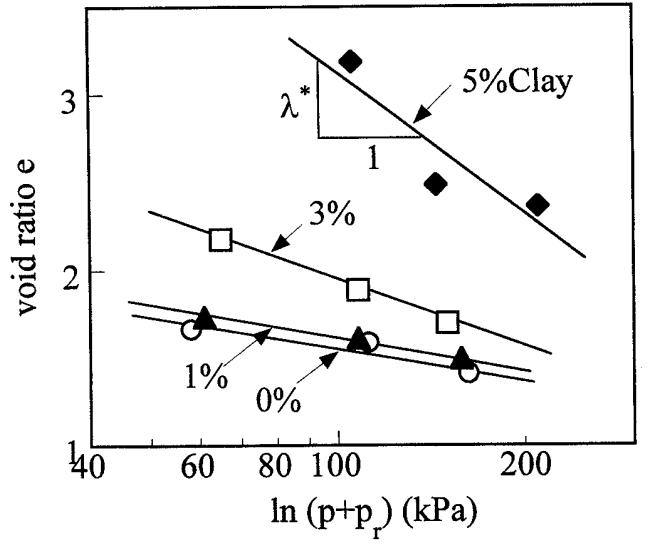

Fig. 18. Failure state in $e-\ln \left(p+p_{r}\right)$ space

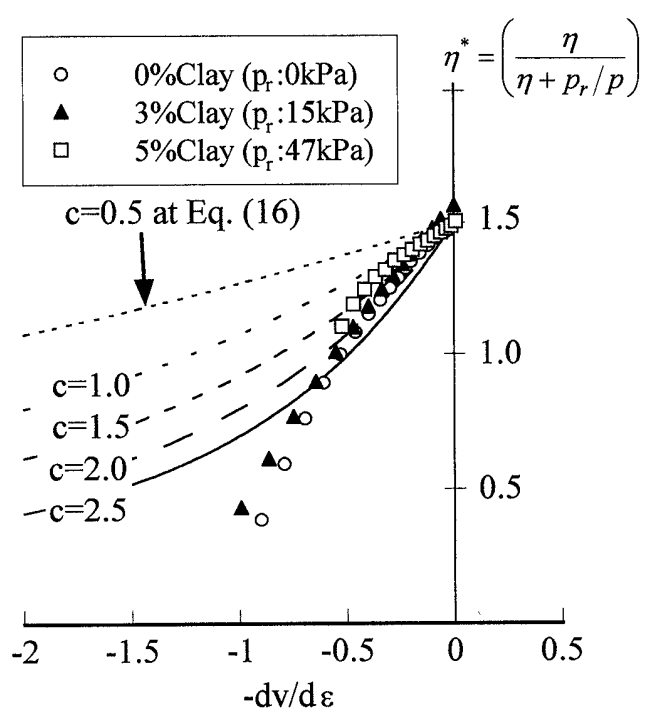

Fig. 19. Stress-dilatancy relationship using modified stress ratio $\eta^{*}$

Table 1. Soil constants of lightly cemented clay

\begin{tabular}{l|c|c|c|c|c|c}
\hline & $\Gamma^{*}$ & $\lambda^{*}$ & $\kappa^{*}$ & $p_{r}(\mathrm{kPa})$ & $M$ & $c$ \\
\hline $0 \%$ Clay & 2.63 & 0.231 & 0.034 & 0 & 1.49 & 2.0 \\
\hline $1 \%$ Clay & 2.76 & 0.250 & 0.029 & 8 & 1.49 & 2.0 \\
\hline $3 \%$ Clay & 4.56 & 0.571 & 0.032 & 15 & 1.49 & 2.0 \\
\hline $5 \%$ Clay & 8.50 & 1.166 & 0.034 & 47 & 1.49 & 2.0 \\
\hline
\end{tabular}

and the corresponding stress ratio $\eta_{f}$ at the confining pressure of $294 \mathrm{kPa}$ are shown in Fig. 21. The model represents the observed results reasonably well, in which $q_{f}$ slightly decreases until the cement content is $3 \%$, while $q_{f}$ of $5 \%$ Clay increases rapidly. On the other hand, $\eta_{f}$ gradually increases with any increase in cement content. Figure 22 shows the peak deviator stress $q_{f}$ against void ratio $e_{i}$. It can be emphasized that the model represents the trend of observed results quite well, in which $q_{f}$ at the same void ratio increases with any increase in cement content. These verifications confirm that the proposed model

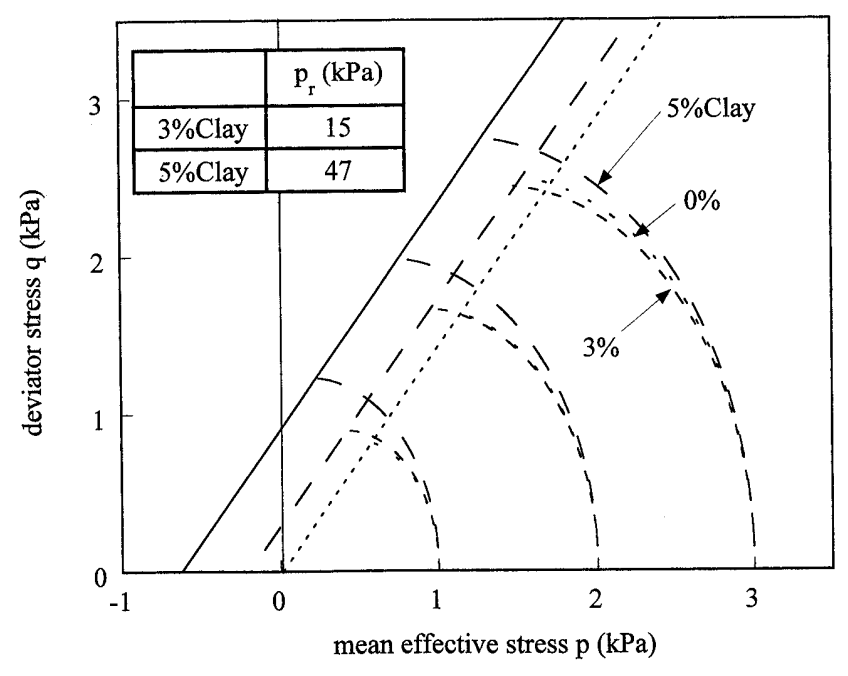

Fig. 20. Predicted stress-path based on presented model

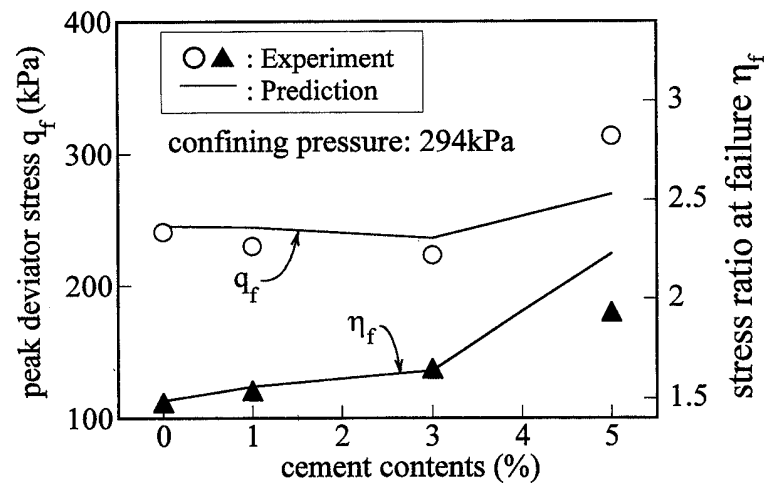

Fig. 21. Comparison of experimental and predicted values of $q_{f}$ and $\eta_{f}$

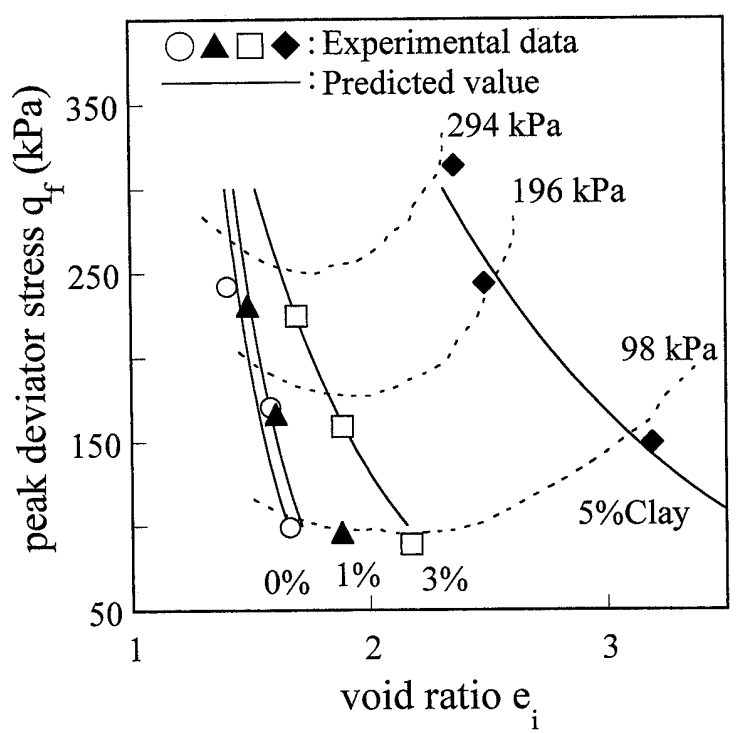

Fig. 22. Predicted $q_{f}$ against void ratio

is effective in estimating the peak strength properties of lightly cemented clay. 


\section{CONCLUSIONS}

In this study, the stress-strain characteristics of lightly cemented clay were discussed from the standpoint of the critical state concept. The experimental findings are summarized as follows: 1) The failure state line in the $p-q$ space is parallel to that of uncemented clay and has a certain intercept $p_{r}$, which characterizes the effect of cementation. The failure state line in the $e-\ln \left(p+p_{r}\right)$ space becomes steeper with the increase in cementation. 2) The stress-dilatancy relationship is almost parallel with that of uncemented clay and is located upward with the increasing cementation. Based on these findings, a failure state concept and an internal dissipated energy for lightly cemented clay were presented. A constitutive model, which includes the soil constant $p_{r}$, is finally proposed. Introduction of a soil constant $p_{r}$ is effective in evaluating the stress-dilatancy relationship and the undrained shear strength of lightly cemented clay.

\section{ACKNOWLEDGEMENT}

A grateful acknowledgement is made to Professor Kouki Zen of Kyushu University and Research Associate Kiyoshi Omine of Kyushu University for their helpful advice and encouragement. The authors also wish to express their thanks to Mr. Michio Nakashima, Technical Officer of Kyushu University, and Mr. Takehiro Morishima, Graduate Student of Kyushu University, for their supports on the experiment. The authors also wish to thank Professor Sarah M. Springman of Swiss Federal Institute of Technology for her critical reading of this paper.

\section{NOTATION}

$\sigma_{v}: \quad$ vertical effective stress

$q$ : deviator stress

$q_{f}$ : peak deviator stress for the undrained triaxial compression test

$e_{i}$ : initial void ratio for the undrained triaxial compression test

$p$ : mean effective stress

$\lambda$ : slope of the critical state line and/or the normally consolidated line in $e-\ln p$ space

$\lambda_{0 \%}: \lambda$ of $0 \%$ Clay

$\eta$ : $\quad$ stress ratio defining $q / p$

$\varepsilon:$ shear strain

$v$ : volumetric strain

$v_{p}$ : plastic volumetric strain

$d v^{p}:$ plastic volumetric strain increment

$d \varepsilon^{p}:$ plastic shear strain increment

$d W_{\text {out }}:$ external dissipated energy work per unit volume

$M$ : slope of the critical state line and the failure state line

$d W_{\text {in }}$ : internal dissipated energy work per unit volume

$X$ : parameter characterized internal dissipated energy work

$\Gamma$ : void ratio for the critical state at which $p$ is unit pressure in $e-\ln p$ space

$p_{r}:$ cementation parameter

$\Gamma^{*}: \quad$ void ratio for the failure state at which $p$ is the unit pressure in $e-\ln \left(p+p_{r}\right)$ space

$\lambda^{*}:$ slope of the failure state line and/or the normally consolidated line in $e-\ln \left(p+p_{r}\right)$ space

$\kappa^{*}:$ slope of the overconsolidated line in $e-\ln \left(p+p_{r}\right)$ space

$p^{*}$ : mean effective stress adding cementation parameter $p_{r}$ to mean effective stress $p$

$\eta^{*}$ : stress ratio defining $q /\left(p+p_{r}\right)$

$c$ : parameter characterized stress-dilatancy relationship defining $X=(c-2) \eta^{*}$

$p_{0}$ : hardening parameter

$p_{0}^{*}$ : hardening parameter adding cementation parameter $p_{r}$ to $p_{0}$

$H_{p}$ : hardening modulus

$p_{c}$ : initial mean effective stress at undrained triaxial compression test

$\eta_{f}:$ stress ratio at failure state

$p_{f}$ : mean effective stress at failure

\section{REFERENCES}

1) Clough, G. W., Sitar, N., Bachus, R. C. and Rad, N. S. (1981): "Cemented stands under static loading," J. Geotech. Engrg. Div. ASCE, Vol. 107, No. 6, pp. 799-817.

2) Gens, A. and Nova, R. (1993): "Conceptual bases for a constitutive model for bonded soils and weak rocks," Proc. 1st Int. Conf. Hard Soils and Soft Rocks, pp. 485-494.

3) Lade, P. V. and Overton, D. D. (1989): "Cementation effects in frictional materials,' J. Geotech. Engrg. Div. ASCE, Vol. 115, No. 10, pp. 1373-1387.

4) Lambe, T. W. (1960): "A mechanistic picture of shear strength in clay," Res. Conf. On Shear Strength of Cohesive Soils. ASCE, pp. 555-580.

5) Leroueil, S. and Vaughan, P. R. (1990): "The general and congruent effects of structure in natural soils and weak rocks," Géotechnique, Vol. 40, No. 3, pp. 467-488.

6) Liu, M. D., Carter, J. P. and Airey, D. W. (1997): “An elastoplastic stress-strain model for cemented carbonate soils," Proc. 14th Int. Conf. on SMFE, Vol. 1, pp. 367-372.

7) Matsuoka, H. and Sun, D. (1993): "A constitutive law for frictional and cohesive materials," JSCE, No. 463/III-22, pp. 163-172 (in Japanese).

8) Roscoe, K. H. and Burland, J. B. (1968): "On the generalized stress-strain behaviour of wet clay. Engineering Plasticity," Cambridge Univ. Press, pp. 535-609.

9) Schofield, A. N. and Wroth, C. P. (1968): Critical State Soil Mechanics, McGraw-Hill Book Company, New York.

10) Terashi, M., Okumura, T. and Mitsumoto, T. (1977): "Fundamental properties of lime-treated soils (1st Report)," Report of the Port and Harbour Research Institute, Vol. 16, No. 1, pp. 3-28 (in Japanese).

11) Terashi, M., Tanaka, H., Mitsumoto, T., Niidome, Y. and Honma, S. (1980): "Fundamental properties of lime and cement treated soils (2nd Report)," Report of the Port and Harbour Research Institute, Vol. 19, No. 1, pp. 33-57 (in Japanese).

12) Terashi, M. (1994): "A new frontier of the ground improvement geosystems," Tsuchi-to-Kiso, JSSMFE, Vol. 42, No. 2, Ser. 433, pp. 1-6 (in Japanese).

13) Ue, S., Fujiwara, H., Takeuchi, J., Fukuda, Y., Sakai, T. and Yanagihara, K. (1997): “Mechanical properties of stabilized kaolin clay by cement type solidifier," JSCE, No. 582/III-41, pp. 217-228 (in Japanese).

14) Yajima, J., Nagaoka, T. and Tanizaki, S. (1997): “Mechanical properties and failure criterion of normally and overconsolidated cement-treated soil," JSCE, No. 561/III-38, pp. 205-214 (in Japanese).

15) Yasufuku, N., Ochiai, H. and Kasama, K. (1997): “The dissipated energy equation of lightly cemented clay in relation to the critical state model," Proc. 9th Int. Conf. Computer Methods and Advances in Geomechanics, pp. 917-922.

16) Yasufuku, N. (1995): "The dissipated energy equation in relation to the critical state model,"' Proc. Int. Sym. on Pre-failure Deformation Characteristics of Geomaterials, Vol. 2. pp. 1223-1224.

17) Yu, Y., Pu, J. and Ugai, K. (1998): "A damage model for soil-cement mixture," Soils and Foundations, Vol. 38, No. 3, pp. 1-12.

18) Zen, K. (1994): "Remedial measures for reclaimed land by premix- 
ing method," Tsuchi-to-Kiso, JSSMFE, Vol. 42, No. 2, No. 433 , pp. 37-42 (in Japanese).

19) Zen, K., Yamazaki, H. and Sato, Y. (1990): "'Strength and deformation characteristics of cement treated sands used for premixing method," Report of the Port and Harbour Research Institute, Vol. 29, No. 2, pp. 85-118 (in Japanese).

\section{APPENDIX A}

Plastic Volumetric Strain during Constant Mean Effective Stress Test

The volumetric strain increments during a constant mean effective stress test $(d p=0)$ are given as follows:

$$
d v^{p}=\frac{1}{H_{p}}\left(\frac{\partial f}{\partial p}\right)\left(\frac{\partial f}{\partial q}\right) d q
$$

where, $H_{p}$ is the hardening modulus expressed by Eq. (18). When substituting Eqs. (19) and (20) into (A-1) and then integrating (A-1), the plastic volumetric strain in the normally consolidated condition can be obtained as follows:

$$
\begin{gathered}
c=1: v^{p}=\frac{\lambda^{*}-\kappa^{*}}{2\left(1+e_{i}\right)} \\
c \neq 1: v^{p}=\frac{c\left(\lambda^{*}-\kappa^{*}\right)}{2\left(1+e_{i}\right)(c-1)} \ln c
\end{gathered}
$$

The parameter $c$ is almost constant irrespective of cement content, as shown in Fig. 19; then the plastic volumetric strain is mainly affected by the slopes of normally and overconsolidated line in the $e-\ln \left(p+p_{r}\right)$ space and void ratio after consolidation, $e_{i}$. The values of $\lambda^{*}-\kappa^{*}$ and $e_{i}$ increase with the increasing cementation as shown in Table 1 and Fig. 5 respectively. Therefore, the amount of plastic volumetric strain increases or decreases with the variations of $\lambda^{*}-\kappa^{*}$ and $e_{i}$. However, such consideration is limited in the case of the normally consolidated condition. The lightly cemented clay tends to be in an overconsolidated condition due to cementation, so the effect of overconsolidation should also be considered to evaluate dilatancy behaviour.

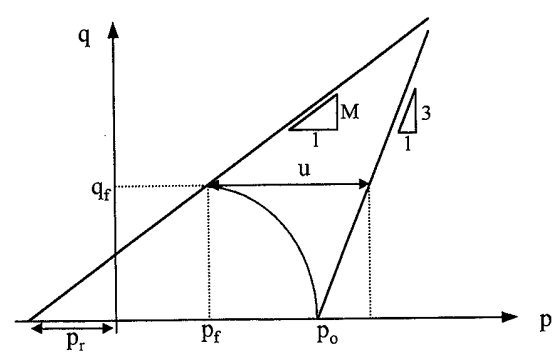

Fig. B-1. Geometrical relationships of undrained shear in $p-q$ space

\section{APPENDIX B}

\section{Excess Pore Water Pressure due to Undrained Shear}

Figure B-1 shows the geometrical relationships of undrained shear in the $p-q$ space. The excess pore water pressure at failure is given as follows.

$$
\begin{aligned}
u & =p_{0}+\frac{1}{3} q_{f}-p_{f} \\
& =\left(p_{0}+p_{r}\right)+\frac{1}{3} q_{f}-\left(p_{f}+p_{r}\right) \\
& =p_{0}^{*}+\frac{1}{3} q_{f}-p_{f}^{*}
\end{aligned}
$$

The values of $p_{f}^{*}$ and $q_{f}$ can be obtained by substituting $\eta^{*}=M$ for Eq. (21) and multiplying $p_{f}^{*}$ by $\mathrm{M}$ respectively. The excess pore water pressure can be expressed as follows:

$c=1: u=\left(1-\left(1-\frac{1}{3} M\right) \times\left(\frac{1}{\sqrt{e}}\right)^{\left(1-\kappa^{*} / \lambda^{*}\right)}\right)\left(p_{0}+p_{r}\right)$

$c \neq 1: u=\left(1-\left(1-\frac{1}{3} M\right) \times\left(\frac{1}{c}\right)^{c\left(1-\kappa^{*} / \lambda^{*}\right) / 2(c-1)}\right)\left(p_{0}+p_{r}\right)$

The values of $p_{r}$ and $\left(1-\left(\kappa^{*} / \lambda^{*}\right)\right)$ increase with the increasing cementation, as shown in Fig. 8 and Table 1 respectively. Therefore, the excess pore water pressure increases as the cementation increases. 